\title{
Brain Perfusion Scintigraphy in Evaluation of Pathogenesis of Fatigue in Patients with Primary Biliary Cholangitis (PBC) - A Pilot Study
}

\author{
Joanna Raszeja-Wyszomirska ${ }^{1,}$, Piotr Zorga $^{2}$, Marcin Kotulski $^{3}$, Bożena Birkenfeld ${ }^{2}$, \\ Piotr Milkiewicz ${ }^{1}$ \\ ${ }^{1}$ Liver and Internal Medicine Unit, Department of Liver, Transplant and General Surgery of Medical University of Warsaw, Warsaw, Poland \\ ${ }^{2}$ Department of Nuclear Medicine, Pomeranian Medical University, Szczecin, Poland \\ ${ }^{3}$ Department of Liver, Transplant and General Surgery of Medical University of Warsaw, Warsaw, Poland
}

\section{Email address:}

joanna.wyszomirska@wum.edu.pl (J. Raszeja-Wyszomirska)

${ }^{*}$ Corresponding author

\section{To cite this article:}

Joanna Raszeja-Wyszomirska, Piotr Zorga, Marcin Kotulski, Bożena Birkenfeld, Piotr Milkiewicz. Brain Perfusion Scintigraphy in Evaluation of Pathogenesis of Fatigue in Patients with Primary Biliary Cholangitis (PBC) - A Pilot Study. International Journal of Clinical and Experimental Medical Sciences. Vol. 3, No. 4, 2017, pp. 42-46. doi: 10.11648/j.jjcems.20170304.11

Received: July 17, 2017; Accepted: August 23, 2017; Published: September 9, 2017

\begin{abstract}
Primary biliary cholangitis (PBC) is an autoimmune cholestatic liver disease characterized by a breakdown of immune tolerance to mitochondrial and nuclear antigens, causing injury to the biliary epithelial cells. Fatigue is the commonest reported symptom in PBC and has a negative impact on patients' perceived quality of life, often through social isolation. It is unrelated to the severity of liver disease and appears unresponsive to current therapies, including ursodeoxycholic acid and transplantation. Fatigue in PBC is complex, with numerous associated peripheral and central nervous system (CNS) features. Initially, cholestasis causes degenerative CNS change affecting areas of the brain regulating autonomic dysfunction and sleep, and these changes lead directly to some manifestations of fatigue and the associated cognitive impairment. The aim of the study was to examine global cerebral blood flow with brain perfusion scintigraphy SPECT in well-defined group of PBC Caucasian patients with verbally reported fatigue. Twenty consecutive PBC female patients (median age 58.9, ranges 38-80; 4 cirrhotic) with mean duration of the disease 3.3 years, were prospectively enrolled into the study. Fatigue Impact Scale (FIS) questionnaire was administered to every patients at the moment of brain examination. Brain perfusion scintigraphy SPECT was performed after intravenous injection of $760-800 \mathrm{MBq}$ of technetium ${ }^{99 \mathrm{~m}}$ labeled exametazime $\left.{ }^{99 \mathrm{~m}} \mathrm{Tc}-\mathrm{HMPAO}\right)$. Then patients were examined using double head gamma camera system, and data were analyzed with dedicated nuclear medicine software. In analyzed cohort the median FIS score was 70.5 points (ranges 21-160), which was higher than previously reported. There were no correlation between age of patients at the SPECT/FIS examination, duration of the disease, the presence of liver cirrhosis, Mayo Risk Score, and FIS domains: Cognitive, Physical and Social, as well as with brain blood flow. However, positive correlation between Cognitive dimension of FIS measure and right frontal lobe perfusion impairment assessed with SPECT technic $(p<0.05)$ was found. The results of this study showed that right lobe perfusion impairment might impact brain function in PBC. Cognitive dimension was stage-independent symptom in analyzed cohort, and cognitive impairment might be, in turn, associated with functional brain lesion.
\end{abstract}

Keywords: Brain Perfusion Scintigraphy, Primary Biliary Cholangitis (PBC), Fatigue, Cognitive Impairment

\section{Introduction}

Primary biliary cholangitis (formerly primary biliary cirrhosis, $\mathrm{PBC}$ ) is a chronic, cholestatic, autoimmune liver disease, affecting mainly middle age women. Management of PBC has traditionally focused on preventing advanced disease, liver failure, and cirrhosis. However, patients often experience profound fatigue, memory impairment, and excessive daytime somnolence which are seemingly 
unrelated to the disease severity. The processes underpinning these symptoms are unknown, and there are currently no effective treatments. Fatigue affects between $60 \%$ and $80 \%$ of PBC patients, with impairment of their quality of life and their perception of their own mental health; it is not related to exercise, nor is it improved by rest [1-3]. The combination of fatigue, cognitive symptoms, and sleep disturbances points to central nervous system dysfunction as a contributing factors [4]. There are some evidences that fatigue in PBC is associated with abnormalities of autonomic function (e.g. baroreflex sensitivity, heart rate variability, blood pressure regulation, orthostatic intolerance) [5-8]. Brain change can occur in PBC, potentially as a result of cholestatic and/or inflammatory processes. This change is linked to systemic symptoms of fatigue and cognitive impairment. The fatigue phenotype appears to be highly stable and its presence is independently associated with a significantly risk of death in general, and cardiac death in particular [9, 10]. It might not disappeared after liver transplantation [11]. The aim of the study was to examine global cerebral blood flow with singlephoton emission computed tomography (SPECT) brain perfusion scintigraphy in well-defined group of $\mathrm{PBC}$ Caucasian patients with verbally reported fatigue.

\section{Patients and Methods}

Twenty consecutive PBC female patients (mean age $58.9 \pm$ 10.2 years) with mean duration of the disease 3.3 years, were prospectively enrolled into the study. $\mathrm{PBC}$ was diagnosed according to the latest guidelines issued by the European Association for the Study of the Liver. All the participant verbally reported chronic fatigue. In four (20\%) liver cirrhosis was diagnosed. Their clinical data are summarized in table 1.

Table 1. Clinical characteristics of the study group.

\begin{tabular}{lll}
\hline & Median (ranges) & Mean + SD \\
\hline Age at diagnosis (years) & $54(37-78)$ & $55.6 \pm 9.6$ \\
Age at examination (years) & $60(38-80)$ & $58.9 \pm 10.2$ \\
Mayo Risk Score (points) & $4.27(2.42-7.72)$ & $4.475 \pm 1.448$ \\
Cognitive dimension FIS (points) & $13.5(3-40)$ & $16.5 \pm 9.6$ \\
Physical dimension FIS (points) & $19.5(4-40)$ & $20.8 \pm 8.9$ \\
Social dimension FIS (points) & $28.5(9-80)$ & $33.2 \pm 17.9$ \\
FIS total score (points) & $61.5(3-80)$ & $70.5 \pm 36.4$ \\
\hline
\end{tabular}

\subsection{Fatigue Impact Scale}

Fatigue Impact Scale (FIS) questionnaire was administered to every patients at the moment of brain SPECT examination. FIS measure was developed and validated in patients witch chronic fatigue syndrome [12] and PBC [13], and consisted of 40 questions to evaluate the impact of perceived fatigue during the last month on 3 subscales: physical, cognitive and psychosocial. Each item uses a 5-grade scale with higher scores denoting increased fatigue. Fatigue Impact Scale was applied in many studies regarding fatigue in PBC patients [1, $10,14-23]$.

\subsection{Single-Photon Emission Computed Tomography (SPECT)}

Brain perfusion scintigraphy was performed after intravenous injection of 760-800 MBq of ${ }^{99 m} \mathrm{Tc}-\mathrm{HmPAO}$. Prior to injection radiochemical purity was controlled using chromatography and yield of labeling was more than $95 \%$. After 20-30 minutes post injection patients were examined using double head gamma camera system (Infinia Hawkeye 4, GE). Acquisitions parameters were: matrix 128 X 128 pixels, 20 seconds per view, 64 views. Raw data was reconstructed with Filtered Back Projection (FBP) and analyzed with nuclear medicine dedicated neurological software (Neuro Gam, Segami).

\subsection{Ethics}

Appropriate informed consent was obtained from each patient included in the study. The study protocol was approved by the ethics committee of Pomeranian Medical University and confronts with the ethical guidelines of the 1975 Declaration of Helsinki (6th revision, 2008).

\subsection{Statistics}

All values were shown as median (and ranges), and mean \pm SD. All statistical tests were performed in SPSS 15.0 program. To determine whether there is correlation between the different domains of FIS tool, and between age and laboratory measures, the Spearman's correlation coefficient was calculated and $p$ values less than 0.05 were considered statistically significant.

\section{Results and Discussion}

\subsection{Results}

In analyzed cohort the median FIS score was 70.5 points (ranges 21-160), which was higher than previously reported $[16-19,22,23]$. There were no correlation between age of patients at the SPECT/FIS examination, duration of the disease, the presence of liver cirrhosis, Mayo Risk Score, and FIS domains: Cognitive (mean $16.5 \pm 9.6$ points), Physical (20.8 \pm 8.9 points) and Social (33.2 \pm 17.9 points), as well as with brain blood flow. However, positive correlation between Cognitive dimension of FIS measure and decreased right frontal lobe perfusion assessed with SPECT technic ( $p=$ 0.026) was found.

\subsection{Discussion}

SPECT brain perfusion scintigraphy showed the reduction of right frontal lobe brain perfusion. This finding was associated with cognitive dimension in PBC chronically fatigued female patients.

Fatigue is a significant problem in approximately $50 \%$ of primary biliary cholangitis patients, impacting their quality of life together with the presence of social dysfunction that accompanies fatigue. The pathogenesis of fatigue remains 
unclear, this symptom is unrelated to the PBC severity and is unresponsive to ursodeoxycholic acid treatment as well as liver transplantation. The complex and multifactorial origin of fatigue is supported with association with depression, autonomic dysfunction and sleep disturbances. It is postulated that chronic cholestasis and inflammation impact autonomic centers in central nervous system leading to cognitive impairments and sleep disturbances. The neuroimaging abnormalities suggest that the brain changes seen in PBC occur early in the pathological process, even before significant liver damage has occurred [24, 25]. Cognitive impairment in $\mathrm{PBC}$ patients was previously reported by groups of Raszeja-Wyszomirska et al. [26] and Newton et al. [27] as the symptom independent of liver disease severity and associated with poorer performance on objective cognitive testing. Cognitive impairment was, in turn, associated with structural brain lesions and autonomic dysfunction, which might predict risk of cognitive decline in the study of Newton et al. [27]

Brain perfusion scintigraphy provides dynamic, functional measures of brain function based on regional cerebral blood flow and tracer accumulation in brain grey matter compared with the static, structural data provided by conventional computerized axial tomography or magnetic resonance imaging (MRI). Mental fatigue was related to brain activity during the fatiguing cognitive task and significant positive relationships were found for cerebellar, temporal, cingulate and frontal regions on MRI [28]. Neuroimaging research in chronic fatigue has found white matter lesions in the frontal area on MRI and cerebral hypoperfusion in the brain stem on SPECT [29], although hypoperfusion has been found in several brain regions, and the findings varied across research centers. Patients with fatigue and without comorbid psychopathology have been found to have more white matter lesions on MRI [30], and more brain stem hypoperfusion [31]. Fischler et al. found positive associations between frontal blood flow, objective and subjective measure of cognitive function, and depressive symptoms [32]. However, these findings were not supported by the result of the other study with SPECT brain perfusion scintigraphy [25]. SPECT abnormalities occur more frequently and in greater numbers than MR abnormalities in patients with chronic fatigue syndrome [33], but there are no study regarding SPECT scanning of cerebral blood flow in PBC patients with fatigue to date.

The study group consisted of females with chronic fatigue in the course of $\mathrm{PBC}$, and, of importance, previous cerebral perfusion studies of normal subjects indicated that flow is higher in women than in men [34]. Patients with chronic fatigue had reduced global cerebral blood flow in Yoshiuchi et al. study [35], supported the previous results regarding global hypoperfusion using SPECT brain imaging [33, 36]. Chronically fatigued patients had decreased blood flow in bilateral middle cerebral artery territories with increased perfusion in cerebellum $[25,31]$. Thus, the result of the recent study, together with the results of Carbone et al. study [37] pointed to possible new aspects of fatigue in PBC, i.e. higher brain sensitivity to reduced blood flow in female patients. This hypothesis might be supported with the result of Ahboucha et al. study. They showed that plasma levels of progesterone metabolites were significantly higher in PBC patients and in those with fatigue in particular. Some of progesterone metabolites are positive allosteric modulators of the gamma-aminobutyric acid type A (GABA-A) receptor and readily cross the blood-brain barrier. It might be that increased inhibition through GABA-A receptors due to the accumulation of neuroinhibitory steroids may represent an important pathophysiological mechanism of fatigue in chronic liver diseases [14].

Paired-pulse trans-cranial magnetic stimulation showed, that PBC patients had a significantly lower central activation before fatiguing exercise and transplanted and non-transplanted patients show similar abnormalities [4]. This finding pointed to potentially irreversible and progressive brain impairment in $\mathrm{PBC}$ patients, and it was supported with the results of the other studies. Newton et al. and Firth et al. noticed that cognitive symptoms (memory and concentration) were prevalent in PBC independently of liver disease severity [27, 38], similarly to findings from this recent study. On the other hand cognitive impairment indicated the role of autonomic dysfunction. Hollingsworth et al. showed the presence of increased cerebral vascular resistance and abnormal cerebral autoregulation in PBC patients, with a potentially important association between the degree of abnormality in structural changes in the globus pallidus. These findings suggested that organic brain injury in PBC might be directly related to autonomic dysfunction [39].

\section{Conclusion}

Chronic fatigue is one of the most debilitating symptom in primary biliary cholangitis affecting a large number of patients. Cholestatic or inflammatory process is linked to systemic symptoms of fatigue and cognitive impairment in PBC. SPECT brain perfusion scintigraphy seems to be useful diagnostic tool in chronically fatigued patients. The results of this pilot study confirmed central nervous system origin of cognitive dimension in PBC patients, independently from severity of liver disease. Right lobe perfusion impairment might impact brain function, and cognitive impairment might be, in turn, associated with functional brain lesion.

\section{References}

[1] Huet PM, Deslauriers J, Tran A, Faucher C, Charbonneau J. Impact of fatigue on the quality of life of patients with primary biliary cirrhosis. Am J Gastroenterol. 2000; 95(3):760-7. doi: 10.1111/j.1572-0241.2000.01857.x. PubMed PMID: 10710071.

[2] Poupon RE, Chretien Y, Chazouilleres O, Poupon R, Chwalow J. Quality of life in patients with primary biliary cirrhosis. Hepatology. 2004; 40(2):489-94. doi: 10.1002/hep.20276. PubMed PMID: 15368455. 
[3] Stanca CM, Bach N, Krause C, Tandon N, Freni MA, Gutierrez JA, et al. Evaluation of fatigue in U.S. patients with primary biliary cirrhosis. Am J Gastroenterol. 2005; 100(5):1104-9. doi: 10.1111/j.1572-0241.2005.41315.x. PubMed PMID: 15842585.

[4] McDonald C, Newton J, Lai HM, Baker SN, Jones DE. Central nervous system dysfunction in primary biliary cirrhosis and its relationship to symptoms. J Hepatol. 2010; 53(6):1095-100. doi: 10.1016/j.jhep.2010.05.036. PubMed PMID: 20810186.

[5] Newton JL, Hudson M, Tachtatzis P, Sutcliffe K, Pairman J, Burt JA, et al. Population prevalence and symptom associations of autonomic dysfunction in primary biliary cirrhosis. Hepatology. 2007; 45(6):1496-505. doi: 10.1002/hep.21609. PubMed PMID: 17538969.

[6] Newton JL, Davidson A, Kerr S, Bhala N, Pairman J, Burt J, et al. Autonomic dysfunction in primary biliary cirrhosis correlates with fatigue severity. Eur J Gastroenterol Hepatol. 2007; 19(2):125-32. doi:

10.1097/01.meg.0000252629.96043.67. PubMed PMID: 17272997.

[7] Newton JL, Allen J, Kerr S, Jones DE. Reduced heart rate variability and baroreflex sensitivity in primary biliary cirrhosis. Liver Int. 2006; 26(2):197-202. doi: 10.1111/j.14783231.2005.01214.x. PubMed PMID: 16448458.

[8] Keresztes K, Istenes I, Folhoffer A, Lakatos PL, Horvath A, Csak T, et al. Autonomic and sensory nerve dysfunction in primary biliary cirrhosis. World J Gastroenterol. 2004;10(20):3039-43. PubMed PMID: 15378789; PubMed Central PMCID: PMCPMC4576268.

[9] Jones DE, Al-Rifai A, Frith J, Patanwala I, Newton JL. The independent effects of fatigue and UDCA therapy on mortality in primary biliary cirrhosis: results of a 9 year follow-up. J Hepatol. 2010; 53(5):911-7. doi: 10.1016/j.jhep.2010.05.026. PubMed PMID: 20800924.

[10] Jones DE, Bhala N, Burt J, Goldblatt J, Prince M, Newton JL. Four year follow up of fatigue in a geographically defined primary biliary cirrhosis patient cohort. Gut. 2006; 55(4):53641. doi: 10.1136/gut.2005.080317. PubMed PMID: 16299032; PubMed Central PMCID: PMCPMC1856154.

[11] Carbone M, Bufton S, Monaco A, Griffiths L, Jones DE, Neuberger JM. The effect of liver transplantation on fatigue in patients with primary biliary cirrhosis: a prospective study. J Hepatol. 2013; 59(3):490-4. doi: 10.1016/j.jhep.2013.04.017. PubMed PMID: 23628322.

[12] Fisk JD, Ritvo PG, Ross L, Haase DA, Marrie TJ, Schlech WF. Measuring the functional impact of fatigue: initial validation of the fatigue impact scale. Clin Infect Dis. 1994;18 Suppl 1: S79-83. PubMed PMID: 8148458.

[13] Prince MI, James OF, Holland NP, Jones DE. Validation of a fatigue impact score in primary biliary cirrhosis: towards a standard for clinical and trial use. J Hepatol. 2000; 32(3):36873. PubMed PMID: 10735604.

[14] Ahboucha S, Butterworth RF, Pomier-Layrargues G, Vincent C, Hassoun Z, Baker GB. Neuroactive steroids and fatigue severity in patients with primary biliary cirrhosis and hepatitis C. Neurogastroenterol Motil. 2008; 20(6):671-9. doi: 10.1111/j.1365-2982.2007.01080.x. PubMed PMID: 18282171.
[15] Ahboucha S, Pomier-Layrargues G, Vincent C, Hassoun Z, Tamaz R, Baker G, et al. Reduced plasma dehydroepiandrosterone sulfate levels are significantly correlated with fatigue severity in patients with primary biliary cirrhosis. Neurochem Int. 2008; 52(4-5):569-74. doi: 10.1016/j.neuint.2007.06.002. PubMed PMID: 17669554.

[16] Biagini MR, Tozzi A, Milani S, Grippo A, Amantini A, Capanni M, et al. Fatigue in primary biliary cirrhosis: a possible role of comorbidities. Eur J Gastroenterol Hepatol. 2008; 20(2):122-6. doi: 10.1097/MEG.0b013e3282flcbda. PubMed PMID: 18188032.

[17] Bjornsson E, Kalaitzakis E, Neuhauser M, Enders F, Maetzel $\mathrm{H}$, Chapman RW, et al. Fatigue measurements in patients with primary biliary cirrhosis and the risk of mortality during follow-up. Liver Int. 2010; 30(2):251-8. doi: 10.1111/j.14783231.2009.02160.x. PubMed PMID: 19922590.

[18] Bjornsson E, Simren M, Olsson R, Chapman RW. Fatigue is not a specific symptom in patients with primary biliary cirrhosis. Eur J Gastroenterol Hepatol. 2005; 17(3):351-7. PubMed PMID: 15716661.

[19] Goldblatt J, Taylor PJ, Lipman T, Prince MI, Baragiotta A, Bassendine MF, et al. The true impact of fatigue in primary biliary cirrhosis: a population study. Gastroenterology. 2002; 122(5):1235-41. PubMed PMID: 11984509.

[20] Newton JL, Gibson GJ, Tomlinson M, Wilton K, Jones D. Fatigue in primary biliary cirrhosis is associated with excessive daytime somnolence. Hepatology. 2006; 44(1):91-8. doi: 10.1002/hep.21230. PubMed PMID: 16800007.

[21] Newton JL, Okonkwo O, Sutcliffe K, Seth A, Shin J, Jones DE. Symptoms of autonomic dysfunction in chronic fatigue syndrome. QJM. 2007; 100(8):519-26. doi: 10.1093/qjmed/hcm057. PubMed PMID: 17617647.

[22] Theal JJ, Toosi MN, Girlan L, Heslegrave RJ, Huet PM, Burak KW, et al. A randomized, controlled crossover trial of ondansetron in patients with primary biliary cirrhosis and fatigue. Hepatology. 2005; 41(6):1305-12. doi: 10.1002/hep.20698. PubMed PMID: 15915460.

[23] Wunsch E, Post M, Gutkowski K, Marlicz W, Szymanik B, Hartleb $\mathrm{M}$, et al. Critical flicker frequency fails to disclose brain dysfunction in patients with primary biliary cirrhosis. Dig Liver Dis. 2010; 42(11):818-21. doi: 10.1016/j.dld.2010.03.017. PubMed PMID: 20430705.

[24] Grover VP, Southern L, Dyson JK, Kim JU, Crossey MM, Wylezinska-Arridge $\mathrm{M}$, et al. Early primary biliary cholangitis is characterised by brain abnormalities on cerebral magnetic resonance imaging. Aliment Pharmacol Ther. 2016; 44(9):936-45. doi: 10.1111/apt.13797. PubMed PMID: 27604637; PubMed Central PMCID: PMCPMC5082539.

[25] Schmaling KB, Lewis DH, Fiedelak JI, Mahurin R, Buchwald DS. Single-photon emission computerized tomography and neurocognitive function in patients with chronic fatigue syndrome. Psychosom Med. 2003; 65(1):129-36. PubMed PMID: 12554824.

[26] Raszeja-Wyszomirska J, Wunsch E, Krawczyk M, Rigopoulou EI, Kostrzewa K, Norman GL, et al. Assessment of health related quality of life in polish patients with primary biliary cirrhosis. Clin Res Hepatol Gastroenterol. 2016; 40(4):471-9. doi: 10.1016/j.clinre.2015.10.006. PubMed PMID: 26621536. 
[27] Newton JL, Hollingsworth KG, Taylor R, El-Sharkawy AM, Khan ZU, Pearce R, et al. Cognitive impairment in primary biliary cirrhosis: symptom impact and potential etiology. Hepatology. 2008; 48(2):541-9. doi: 10.1002/hep.22371. PubMed PMID: 18563843.

[28] Cook DB, O'Connor PJ, Lange G, Steffener J. Functional neuroimaging correlates of mental fatigue induced by cognition among chronic fatigue syndrome patients and controls. Neuroimage. 2007; 36(1):108-22. doi: 10.1016/j.neuroimage.2007.02.033. PubMed PMID: 17408973.

[29] Lange G, Wang S, DeLuca J, Natelson BH. Neuroimaging in chronic fatigue syndrome. Am J Med. 1998; 105(3A):50S-3S. PubMed PMID: 9790482.

[30] Lange G, DeLuca J, Maldjian JA, Lee H, Tiersky LA, Natelson BH. Brain MRI abnormalities exist in a subset of patients with chronic fatigue syndrome. J Neurol Sci. 1999; 171(1):3-7. PubMed PMID: 10567042.

[31] Costa DC, Tannock C, Brostoff J. Brainstem perfusion is impaired in chronic fatigue syndrome. QJM. 1995; 88(11):767-73. PubMed PMID: 8542261.

[32] Fischler B, D'Haenen H, Cluydts R, Michiels V, Demets K, Bossuyt A, et al. Comparison of ${ }^{99 \mathrm{~m}} \mathrm{Tc}$ HMPAO SPECT scan between chronic fatigue syndrome, major depression and healthy controls: an exploratory study of clinical correlates of regional cerebral blood flow. Neuropsychobiology. 1996; 34(4):175-83. PubMed PMID: 9121617.

[33] Schwartz RB, Garada BM, Komaroff AL, Tice HM, Gleit M, Jolesz FA, et al. Detection of intracranial abnormalities in patients with chronic fatigue syndrome: comparison of MR imaging and SPECT. AJR Am J Roentgenol. 1994;
162(4):935-41. doi: 10.2214/ajr.162.4.8141020. PubMed PMID: 8141020.

[34] Gur RE, Gur RC. Gender differences in regional cerebral blood flow. Schizophr Bull. 1990; 16(2):247-54. PubMed PMID: 2374883.

[35] Yoshiuchi K, Farkas J, Natelson BH. Patients with chronic fatigue syndrome have reduced absolute cortical blood flow. Clin Physiol Funct Imaging. 2006; 26(2):83-6. doi: 10.1111/j.1475-097X.2006.00649.x. PubMed PMID: 16494597.

[36] Ichise M, Salit IE, Abbey SE, Chung DG, Gray B, Kirsh JC, et al. Assessment of regional cerebral perfusion by ${ }^{99 \mathrm{~m}} \mathrm{Tc}$ HMPAO SPECT in chronic fatigue syndrome. Nucl Med Commun. 1992; 13(10):767-72. PubMed PMID: 1491843.

[37] Carbone M, Mells GF, Pells G, Dawwas MF, Newton JL, Heneghan MA, et al. Sex and age are determinants of the clinical phenotype of primary biliary cirrhosis and response to ursodeoxycholic acid. Gastroenterology. 2013; 144(3):560-9 e7; quiz e13-4. doi: 10.1053/j.gastro.2012.12.005. PubMed PMID: 23246637.

[38] Frith J, Fattakhova G, Jones DE, Henderson E, Wilton K, Day $\mathrm{CP}$, et al. Cognitive impairment in non-cirrhotic chronic liver disease is unrelated to liver disease severity but associated with ineffective baroreflex function. Gut. 2012; 61(7):1101-3. doi: 10.1136/gutjnl-2011-301216. PubMed PMID: 22057052.

[39] Hollingsworth KG, Jones DE, Taylor R, Frith J, Blamire AM, Newton JL. Impaired cerebral autoregulation in primary biliary cirrhosis: implications for the pathogenesis of cognitive decline. Liver Int. 2010; 30(6):878-85. doi: 10.1111/j.14783231.2010.02259.x. PubMed PMID: 20492494. 